\title{
HORIZONTES
}

Revista Semestral do Programa de Pós-Graduação Stricto Sensu em Educação da Universidade São Francisco Volume 32 Número 1 Janeiro/Junho de 2014

ISSN 0103-7706

\begin{abstract}
A revista Horizontes é um veículo de divulgação e debate da produção científica na área de Educação e está vinculada ao Programa de Pós-Graduação Stricto Sensu em Educação da Universidade São Francisco, Itatiba/SP. O propósito da revista é servir de fórum para a apresentação de pesquisas desenvolvidas, estudos teóricos e resenhas na área de Educação, em suas vertentes históricas, culturais e de práticas educativas. Com vistas a manter uma interlocução com pesquisadores nacionais e internacionais, a revista aceita publicações nas línguas portuguesa, inglesa, francesa e espanhola. Os textos publicados são submetidos a uma avaliação às cegas pelos pares, componentes do conselho editorial ou consultores ad hoc. Os conteúdos não refletem a posição, opinião ou filosofia, nem do Programa de PósGraduação nem da Universidade São Francisco.

A revista é composta de dossiês com temática educacional coerente com a política editorial da mesma e/ou artigos de demanda espontânea encaminhados e aprovados para publicação. Os direitos autorais das publicações da Horizontes são da Universidade São Francisco, permitida apenas ao autor a reprodução do seu próprio material, previamente autorizado pelos editores da revista. As transcrições e traduções são permitidas, desde que no limite dos 500 vocábulos e mencionada a fonte.
\end{abstract}

\section{Dossiê: Gêneros Textuais e Ensino}

\author{
Editores \\ Adair Mendes Nacarato \\ Jackeline Rodrigues Mendes \\ Paula Leonardi \\ Organizador do Dossiê \\ Luzia Bueno
}

\section{Conselho Editorial}

Ademir Donizeti Caldeira - UFScar Alfredo Veiga-Neto - UFRGS

Beatriz Maria Eckert-Hoff - Unianchieta

Carlos Alberto de Oliveira - Unitau Celi Espasandin Lopes - Unicsul

Celina Ap. Garcia de Souza Nascimento - UFMS

Daniel Clark Orey - UFOP

Dario Fiorentini - Unicamp

Décio Gatti Júnior - UFU

Denise Silva Vilela - UFScar

Elisabeth Ramos da Silva - Unitau

Elizeu Clementino de Souza - UNEB

Elzira Yoko Uyeno - Unitau

Ernesto Sérgio Bertoldo - UFU

Gelsa Knijnik - UNISINOS

Juliana Santana Cavallari - Univás

Maria Ângela Borges Salvadori-USP
Maria Auxiliadora Bueno Megid - Puccamp

Maria Carolina Galzerani Boverio - Unicamp

Maria Cristina Soares Gouveia - UFMG

Maria Gorete Neto - UFMG

Maria José Rodrigues Faria Coracini - Unicamp

Maria Laura Magalhães Gomes - UFMG

Maria Tereza Menezes Freitas - UFU

Maura Corsini Lopes - UNISINOS

Maurício Rosa - ULBRA

Patrick Anderson - Université de Franche-Comté

Rebecca Rogers - Université Paris Descartes

Renata Prenstteter Gama - UFScar

Rita de Cássia Galego - USP

Rosana Giaretta Sguerra Miskulin - UNESP/RC

Samuel Edmundo López Bello - UFRGS

Vera Lúcia Gaspar da Silva - UDESC

Edição

Programa de Pós-graduação Stricto Sensu em Educação

Projeto Gráfico, Revisão e Diagramação
Samanta Mazzolini 


\section{Publicações:}

Programa de Pós-Graduação Stricto Sensu em Educação

Secretaria de Pós-Graduação

Apoio Executivo às Comissões de Pós-Graduação

Av. Alexandre Rodrigues Barbosa, 45 - Centro

CEP: $13251-900$ Itatiba-SP

Tel: (11) 4534-8040/ 4534-8080 Fax: (11) 4524-1933

Homepage: http://www.saofrancisco.edu.br/itatiba/mestrado/educacao

Editora Universitária São Francisco - EDUSF

Av. Francisco de Assis, 218

CEP: 12916-900 Bragança Paulista - SP

Tel: (11) 4534-8040 Fax: (11) 4524-1933

Homepage: http://www.saofrancisco.edu.br/edusf

Horizontes / Universidade São Francisco. -- Vol. 14 (1996)-. -- Bragança Paulista:

Editora Universitária São Francisco, 1996-

v. : il.

Anual, 1996-2003; semestral, 2004-

Continuação de: Revista das Faculdades Franciscanas (1983-1985); Revista da Universidade São Francisco (1986-1989); Horizontes: revista de ciências humanas (1990-1995)

Disponível on-line: http://www.usf.edu.br/revistas/horizontes

ISSN 0103-7706 (versão impressa)

ISSN 2317-109X (versão on-line)

1.Ciências humanas - Periódicos. 2. Linguagem - Periódicos. 3. Educação Periódicos. 4. Educação matemática - Periódicos 5. Historiografia - Periódicos. I. Universidade São Francisco.

Ficha catalográfica elaborada pelas Bibliotecárias do Setor de Processamento Técnico da Universidade São Francisco.

Pede-se permuta

Se pide canje

We ask for Exchange

On demande l'échange

Indexação em:

Man bittet um Austausch

Psicodoc (Espanha); Clase (México); Francis

Si richiede lo scambio (França). 


\section{Sumário}

5

Editorial

Dossiê

$7 \quad 0$ gênero textual reportagem impressa em sala de aula: uma proposta de trabalho a partir da elaboração de Modelo Didático de Gênero e de Sequência Didática

Rosangela Oro Brocardo

Terezinha da Conceição Costa-Hubes

21 Oênero textual comentário jornalístico radiofônico no ensino do oral: processo de elaboração de um modelo didático

Carla Messias

35 A elaboração de um artigo científico: subsídios à apropriação desse gênero textual Juliana Gava B. Silva

Maria Teresa Baptistella Ferrari Pereira

Luzia Bueno

49 Os efeitos da introdução de uma nova ferramenta de ensino nas práticas docentes em sala de aula - o caso de uma sequência didática

Luciana Graça

Luísa Álvares Pereira

$57 \quad$ trabalho com uma sequência didática de receitas em língua inglesa em uma escola pública Ana Paula Marques Beato-Canato

Vera Lúcia Lopes Cristovão

73 O plano de estudos: um gênero textual acadêmico para pleitear intercâmbio

Emily Caroline da Silva

Eliane Gouvêa Lousada

89 La obra literaria en la enseñanza de las lenguas y los géneros textuales

Dora Riestra

Artigos

99 As imagens de Debret no ensino de história no Liceu do Ceará, Fortaleza (Bairro Jacarecanga) Antônio Germano Magalhães Junior

Adriano Cecatto

111 Biopolítica e espaço escolar: subjetividade e racismo no Brasil

Mozart Linhares da Silva

123 Projeto Integrado de Prática Educativa: uma experiência no curso de matemática

Fabiana Fiorezi de Marco

Maria Teresa Menezes Freitas

Anna Regina Lanner de Moura 
135 Resenha: Ambientes Digitais

Acir Mário Karwoski

Julio Cesar Oliveira Bernardo

139 Relação das teses defendidas no Programa de Pós-Graduação Stricto Sensu em Educação da Universidade São Francisco no período de janeiro a junho de 2014

143 Relação das dissertações defendidas no Programa de Pós-Graduação Stricto Sensu em Educação da Universidade São Francisco no período de janeiro a junho de 2014

149 Normas para publicação

Publishing Norms 


\section{Editorial}

Este volume da revista Horizontes - revista semestral do Programa de Pós-Graduação Stricto Sensu em Educação da Universidade São Francisco - apresenta o dossiê "Gêneros textuais e ensino" que visa enriquecer as discussões sobre o trabalho com gêneros textuais em nosso país, mas em diálogo com as pesquisas de outros países, como a Argentina e Portugal. Assim, mantém-se a proposta de dar continuidade ao formato temático iniciado em 2007, integrando, assim, o seu $32^{\circ}$ volume na modalidade de dossiê. Além dos artigos do dossiê, assim como os números anteriores, este, também, apresenta artigos de reflexão crítica oriundos de demanda espontânea, sempre submetidos à avaliação do comitê científico e aprovados por dois de seus membros. Tanto os artigos que se enquadram no dossiê, quanto os de demanda espontânea, encontram-se articulados nas três linhas de pesquisa que imputam uma organicidade ao programa de Pós-Graduação Stricto Sensu em Educação, quais sejam: Linguagem, Discurso e Práticas Educativas; Matemática, Cultura e Práticas Pedagógicas e História, Historiografia e Ideias Educacionais ao abordarem o ensino, a linguagem e o trabalho docente no diálogo com a perspectiva histórico cultural.

O dossiê "Gêneros textuais e ensino", que traz artigos do Brasil, da Argentina e de Portugal, foi organizado por Luzia Bueno. Desde o lançamento dos PCNs, na década de 1990, iniciouse uma grande discussão no Brasil sobre o trabalho com gêneros textuais, gerando vários estudos e publicações. Este volume é dedicado a essa discussão sobre os gêneros textuais no ensino no Brasil, na Argentina e em Portugal, uma vez que o ensino, por meio dos gêneros textuais, vem se mostrando uma tendência importante, ainda que continue a exigir sérias reflexões para que se garanta um trabalho didático que leve ao desenvolvimento dos alunos. Os artigos desse volume nos apresentam algumas dessas reflexões. No primeiro artigo, "O gênero textual reportagem impressa em sala de aula: uma proposta de trabalho a partir da elaboração de Modelo Didático de Gênero e de Sequência Didática", as autoras Rosangela Oro Brocardo e Terezinha da Conceição Costa-Hubes (UNIOESTE) nos trazem uma discussão sobre como viabilizar um trabalho com gêneros textuais na escola. Em "O gênero textual comentário jornalístico radiofônico no ensino do oral: processo de elaboração de um modelo didático", o segundo artigo deste volume, Carla Messias (PUC-SP e UNIGE- Universidade de Genebra) reflete sobre o processo de elaboração de um modelo didático para o gênero comentário jornalístico radiofônico, produzido por meio da análise de exemplares desse gênero. $\mathrm{O}$ terceiro artigo é "A elaboração de um artigo científico: subsídios à apropriação desse gênero textual" de Juliana Gava B. Silva, Maria Teresa Baptistella Ferrari Pereira e Luzia Bueno (USF- Itatiba). Neste, as autoras visam apresentar os resultados de uma pesquisa desenvolvida com o objetivo de depreender características do artigo científico a fim de fornecer um instrumento para preparar os alunos para a escrita desse gênero e os professores para o seu ensino. Luciana Graça e Luísa Álvares Pereira da Universidade de Aveiro, em Portugal, escrevem o quarto artigo "Os efeitos da introdução de uma nova ferramenta de ensino nas práticas docentes em sala de aula - o caso de uma sequência didática" que pretende fornecer dados que contribuam para a discussão em torno da importância das ferramentas de ensino de que o docente dispõe e/ou pode dispor, na sua prática de ensino. No quinto artigo, "O trabalho com uma sequência didática de receitas", Ana Paula Marques Beato (UFRJ-Rio de Janeiro) e Vera Lúcia Lopes Cristóvão (UEL-Paraná) apresentam uma experiência sobre o trabalho com línguas na rede regular pública de ensino de Joinville planejado em sequências didáticas organizadas em torno de gêneros textuais. Em "O plano de estudos: um gênero textual acadêmico para pleitear intercâmbio", no sexto artigo, Emily Caroline da Silva e Eliane Gouvêa Lousada (USPSão Paulo) apresentam um texto que visa contribuir para a expansão de pesquisas focadas na didática de gêneros textuais acadêmicos. O último artigo deste dossiê, "La obra literaria en la enseñanza de las lenguas y los géneros textuales", de Dora Riestra, da Universidade Nacional de Rio Negro, da Argentina traz uma discussão sobre signos, gêneros textuais e a literatura, visando refletir sobre a necessidade de uma reformulação no trabalho com o texto literário.

Os demais artigos contemplados pelo presente volume são os seguintes: $\mathrm{O}$ artigo "As imagens de Debret no ensino de História no Liceu do Ceará, Fortaleza (bairro Jacarecanga)", de Antônio Germano Magalhães Junior (Universidade Estadual do Ceará/Fortaleza) e Adriano Cecatto (Universidade do Estado do Rio Grande do Norte/Assú), apresenta uma discussão sobre a 
prática de ensino dos professores de História a partir do uso de imagens, particularmente as iconografias de Jean-Baptiste Debret. No artigo "Biopolítica e espaço escolar: subjetividade e racismo no Brasil", de Mozart Linhares da Silva (PPGEDU - UNISC), o autor problematiza a escola enquanto dispositivo biopolítico, sob a ótica das estratégias de governamento das diferenças étnico/raciais e dos processos de produção de subjetividades. $\mathrm{O}$ artigo "Projeto Integrado de Prática Educativa: uma experiência no curso de matemática", de Fabiana Fiorezi de Marco, Maria Teresa Menezes Freitas (UFU) e Anna Regina Lanner de Moura (UNICAMP), discute uma proposta de trabalho desenvolvida em uma pesquisa realizada no Projeto Integrado de Prática Educativa - PIPE - da Faculdade de Matemática da Universidade Federal de Uberlândia. Além dos artigos apresentados, o atual volume da revista Horizontes conta com a resenha crítica do livro "Ambientes digitais: reflexões teóricas e práticas", publicado pela
Editora Cortez em 2013. Este livro é de autoria de Denise Bértoli Braga, professora titular do Departamento de Linguística Aplicada da Unicamp, e foi resenhado por dois professores da Universidade Federal do Triângulo Mineiro (UFTM). O volume se encerra com a apresentação das dissertações desenvolvidas e defendidas no segundo semestre de 2013, no Programa de PósGraduação Stricto Sensu em Educação, mediante a publicação de seus resumos. Com a publicação de mais este volume, o Programa de Pós-Graduação Stricto Sensu em Educação, representado pelos seus editores, espera poder continuar sendo veículo para os diálogos entre trabalhos que, investigando diversas questões e utilizando-se de diferentes referenciais e fontes, participam da disseminação de ideias e pesquisas no campo educacional.

Adair Mendes Nacarato Jackeline Rodrigues Mendes Paula Leonardi 